\title{
'If you are having a go at me, I am going to have a go at you': The changing nature of social relationships of bank work under Performance Management
}

\author{
Knut Laaser ${ }^{1}$ \\ University of Stirling, UK
}

\begin{abstract}
Over the last three decades work and employment in the private and public sector are increasingly subject to marketisation processes. A defining feature of marketised employment is the rise of performance management systems (PMS). This article utilises a novel framework of Sayer's moral economy approach and labour process theory to explore the changing nature of bank work and social relationships between branch managers and branch workers before and after the implementation of PMSs in UK banks. This article illustrates how the social and moral texture of the social relationships between branch workers and their managers deteriorated after the implementation of PMS, resulting in the rise of hostile forms of engagement.
\end{abstract}

Key words: Bank work; Labour Process Theory; Moral Economy; Performance Management Systems; Social relationships at work.

\section{Introduction}

Over the last three decades, work and employment in the private and public sector has been increasingly subject to marketisation processes that encapsulate the dependence of firms on financial markets and the cascading down of short-term market needs into the firm with ample consequences for the quality of work (Thompson, 2013). Indeed, there is a growing recognition of a deterioration of job quality in the context of large-scale organisational restructuring along market demands, pushing for a reduction of labour costs and closer performance monitoring within an intensified labour process (Carré et al., 2012; Carter et al.,

\footnotetext{
${ }^{1}$ Corresponding author: Knut Laaser, Stirling University Management School, Stirling FK9 4LA, UK. Email: knut.laaser@stir.ac.uk
} 
2014). Ample evidence reveals that performance management systems (PMSs) in routinised workplaces embody a particular type of marketised employment, being primarily concerned with the 'full utilisation of employee labour power' (Thompson, 2011:362) via individualised performance targets, tight managerial surveillance and disciplinary policies that implement market discipline in the firm (Ellis and Taylor, 2006; Newsome et al., 2013). The impact of PMSs on the labour process have been portrayed as particularly radical in white collar workplaces that have been traditionally understood as featuring privileged employment conditions and informal ties between front-line managers and employees (Halford et al., 1995; Hassard et al., 2009; Lockwood, 1957). Indeed, under performance driven workplace regimes white collar employees and their managers experienced a degradation and intensification of their work, leading to rising levels of friction between employees and their managers (Carter al al., 2014; Fevre et al., 2012; Taylor, 2013). Yet, empirical evidence that combines an in-depth account of the changing white collar labour process under PMSs and its impact on the social and moral relationships between employees and managers remain scant.

Based on qualitative in-depth interviews with branch workers (BWs) and branch managers (BMs) from UK banks, the article examines the changing labour process and its social and moral relationships between BWs and BMs against the backdrop of the transformation of the conservative and bureaucratic workplace regime towards a PMS driven employment relationship (Ellis and Taylor, 2010; Halford et al., 1995). The present article is based on a novel theoretical framework that combines key aspects of labour process theory (LPT) and Andrew Sayer's moral economy (ME), fusing the strength of the materialist workplace theory and its focus on changing work and management practices with a strong understanding of human and moral agency. Through the lens of LPT and ME, this article reveals that the privileged employment conditions in banks that fostered a social compromise and shared moral understandings between employees and their managers before its 
marketisation became dismantled and replaced with an intensified labour process and conflict-ridden relationships under PMS. The article argues further that the theoretical lens of LPT and ME offers a holistic frame that combines a critical analysis of trends in work and employment with a thick conceptualisation of actors as social and moral beings, paving the way for an analysis of the social and relational consequences of work and employment under capitalism.

\section{The changing nature of white collar work and relationships between managers and employees}

Sociological literature on the nature of white collar work and the relationship between managers and employees in white collar settings are traditionally embedded in wider debates regarding the distinctive class position and privileged employment conditions of clerical workers vis-à-vis manual workers (Carter, 1985; Crompton and Jones, 1984). In the first half of the twentieth century, the patriarchal employment structure featured high levels of job security, incremental pay scales, varying discretion levels at work and modest but stable career opportunities for male clerical workers (Crompton, 1989; Lockwood, 1958). Within this environment, relationships between clerical workers and their immediate supervisors were often characterised by personal ties and trust over informal work effort norms. Meanwhile, the relationship between managers and clerical workers was embedded in a moral order which was based on a paternalist and unitary ideology that masked the power asymmetry in the workplace by a focus on common and shared objectives (Heritage, 1977).

A widely shared position in labour process research is that from the 1960s onwards the implementation of scientific management techniques and ICT in clerical work settings triggered waves of downskilling and rationalisation (Braverman, 1974), while the authority and discretion of middle and front-line managers (FLM) became constrained by centralised 
decision-making processes (Carter, 1985). Consequential, middle and FLMs increasingly performed supervisory and control functions, resulting in a disconnection of informal ties between clerical workers and their managers and rising levels of conflict and instrumental forms of engagement between management and labour (Crompton and Jones, 1984).

Despite the well-documented degradation of clerical work in many workplaces, some areas of white collar employment encapsulated a variety of traditional clerical tasks and continued to be characterised by relatively privileged employment conditions and more informal front-line management-employee relationships. For example, Carter et al.'s ( 2014) research on the changing class relations in Her Majesty's Revenue and Customs (HMRC) illustrate that prior to the subsequent implementation of Lean Management (LM) in 2005 the relationship between front-line managers (FLM) and employees was characterised by shared interests and personal ties in the context of relatively high levels of discretion in the labour process. However, Carter and colleagues argue that under LM work became subject to standardisation, tighter control and ever increasing performance pressures for managers and employees, resulting in a rise of conflict-ridden relationships between FLMs and employees (see also Fevre et al., 2012; Hassard et al., 2009).

Similar observations can be found in the literature on employment relations in the UK banking industry. For the majority of the Post-second world war era clearing banks were labelled as ‘employing organizations par excellence' (Gall, 2008:xiv), offering lifetime employment and modest but stable career opportunities (Cressey and Scott, 1992; Halford et al., 1995). Relationships between bank clerks and their managers are characterised as traditionally embedded in an unitary ideology that promoted a moral order, featuring shared interest and loyalty (Heritage, 1977). Following on from this, Blackburn (1967:57) among others enthusiastically concludes that '(b)anking is different from other occupations; in banking there is no split between labour and capital; no "us" and "them". 
Employment conditions and the social relations of production in the banking industry transformed radically with the launch of the Financial Service Act (FSA) under the Thatcher regime in the late 1980s that resulted in a liberalisation of the financial market (Watson, 2004). In this environment clearing banks radically restructured the employment relationship throughout the nineties, engaging in large scale labour cost cutting that rendered management as well as employees vulnerable to layoffs (Cressey and Scott, 1992). Parallel to the restructuring banks went through was the redesign of the branch as retail unit that focusses primarily on the marketing and selling of financial products to customers (Ellis and Taylor, 2010). Arguably, this shift reflects the wider development of a financialisation of society that pushes for an increasing dependency of households on the financial market 'as debtors and as asset holders' (Lapavitsas, 2011:612). Fevre et al. (2012) suggest that as a result of the combination of the standardisation of branch work with the replacement of the service culture in favourite of a product sales culture, bank workers experienced a violation of their moral principles, resulting in rising levels of friction between bank workers and branch managers in general and ill-treatment at work in particular.

While the changing conditions of white collar employment in general and bank work in particular are well documented, in-depth accounts of the changing social and moral relationships between employees and their managers in the context of the radical transformation of the labour process remain scant. Arguably, the neglect of a focus on the moral dimensions of employment in critical employment studies reflects the wider 'divorce of the study of morality from [that of] political economy' (Sayer, 2000: 86) that is embodied in the view of economic practices under capitalism as disembedded from the social and moral sphere. In order to fuse a strong conceptualisation of human agency and the moral dimensions of employment with a critical understanding of changing workplace practices in the context of wider shifts in the political economy, the next section combines labour process 
theory (LPT) with Sayer's moral economy (ME) approach. This theoretical lens guides the exploration of the changing labour process and the social and moral relationships between branch workers and their managers in the context of the shift from the conservative bureaucracy towards a PMS driven employment relationship.

\section{The moral economy of the labour process}

LPT has a rich history of conceptualising the workplace as a contested terrain. Here 'struggles over divergent interests and identities' (Thompson and Newsome, 2004:150) take place against the backdrop of the indeterminacy of labour and the structured antagonism of the employment relationship (Thompson, 1989). The indeterminacy of labour points towards the contingency and variability of labour power and managerial practices that aim via a variety of strategies to deploy and maximise labours work effort (Smith, 2006). Following on from this, the employment relationship is necessarily antagonistic and exploitative as labour is a key factor in the production process through which organisations create surplus value, while workers do not own the fruits of their labour nor decide how their labour power is utilised (P.Edwards, 1986). Hence, conflict is a persistent feature of the relationship between management and labour as both groups possess diverging interests regarding workplace conditions in general and the utilisation of labour power in particular (Edwards, 1979:111).

However, LPT approaches do not suggest that the struggle over interests between labour and capital follows a pre-determined pattern, but is rather context dependent and shaped by the collective agency of labour and capital (Thompson and Newsome, 2004). Fusing LPT insights and wider industrial relation theories, Edwards and colleagues (2006) argue that compromise at work reflects dynamic negotiations over control and developmental 
concerns between labour and management that entail formal and informal bargaining over concrete forms of managerial power on the one hand and interests over developmental aspects, such as investment in training and technology that affect the quality of jobs on the other (Edwards et al., 2006). In this way, 'the competing rationales of management and labour sometimes run in parallel, and sometimes not' (Bélanger and Edwards, 2007:715). Edwards and colleagues provide a rich conceptualisation of the interplay between structuring conditions and the formation of compromise and conflict at work in the context of the wider inequalities of a political economy. Yet, the relationship between managers and employees is theorised as being exclusively of economic nature, driven by rational interests that translate into various forms of conflict or compromise at work. Hence, the social and moral dimensions of relationships at work between employees and managers that is embodied in the interplay of people's complex needs and concerns as economic, but also social and moral beings are neglected. This article argues that fusing Sayer's moral economy (ME) with LPT enhances an understanding of the social relationships between employees and their managers as control, social and moral relationship that is shaped by the particularities of workplace regimes and people's complex needs and concerns.

The concept of moral economy (ME) has a rich heritage of analysing the dialectical relationship between economic practices, communities and people in pre-market and capitalist societies. One of the most familiar ME accounts comes from Karl Polanyi's much celebrated great transformation thesis. Polanyi suggests that the moral order of pre-market societies in which labour and land 'formed part of the organic structure of society' (Polanyi, 1968:35) deteriorated under capitalism and its tendency to subsume communities, people and their labour power under market forces. In order to protect society from dehumanisation posed by marketisation, Polanyi (1957) famously argued that counter movements, primarily 
from the state, emerge to constrain market forces via regulatory initiatives and the development of a welfare state.

Marrying a neo-Aristotelian moral philosophy with a radical political economy approach that includes Polanyi’s work, Andrew Sayer's ME concept $(2000 ; 2005 ; 2011)$ conceptualises economic practices under capitalism as always embedded, even though to different degrees, in the social and moral sphere of society and people's moral sentiments. Here, a dialectical relationship between economic actions and people's morality emerge, suggesting that capitalist practices shape, but also are re-shaped, by webs of norms and values of humanity, affecting and being affected by human evaluations and people's moral sentiments (Sayer, 2000). Rejecting the tendency in social sciences to reduce morality to prevalent norms and discourses, this moral economy approach conceptualises actors as social and sentient beings that are economically and psychologically dependent on others, possessing the capacity to develop throughout their life course complex needs and commitments to practices and people (Sayer, 2011).

At the heart of Sayer's ME approach is the concept of lay morality that refers to peoples' on-going monitoring and evaluation of their own and others actions and faring in the context of their complex needs and understandings of what practices constitute well-being or, respectively, trigger suffering (Sayer, 2005). Yet, people's agency and lay morality is 'constrained and enabled (...) by social structures and cultural discourses' (Sayer, 2011: 86), so that socio-economic positions in general and wider inequalities of the political economy in particular limit, but do not colonise people's agency and diverse needs and concerns (Sayer, 2005). Here, Sayer identifies a tension between economic practices under capitalism and human needs and concerns. This is particularly inherent in capitalist organisations that aim to purify its practices and narrow employees' needs and concerns to those that are essential for profit maximisation (Sayer, 2007). Yet, Sayer argues that human needs and concerns tend to 
spill over the instrumental frame of the employment relationship, which is visible in responses and social relationships that 'may vary considerably in how far they conform to the organisation's priorities' (Sayer, 2006:206).

Even though ME and LPT place their emphasis on different layers of analysis, both approaches share essential theoretical and ontological assumptions. At the heart of LPT and ME is the dialectical relationship between the separate and objective realm of capitalist relations and people's agentic capacities that enables them to modify, resist, but also reinforce the materialist forces and normative pressures they are exposed to. In this way, both approaches are not deterministic, featuring a strong account of human agency that conceptualises employees as creative and will-full actors who react in different ways to the material realities of work and the employment relationship (Sayer, 2007; Thompson et al., 2000). Following on from this, LPT and ME share a conceptualisation of organisations under capitalism as instrumental institutions that utilise labour as a means to the end of profit maximisation. Here, a shared understanding of labour as an exploitable resource emerges whose indeterminacy triggers a variety of different managerial practices that aim to control and capture it (Smith, 2006).

Meanwhile, LPT and ME complement each other in several ways. LPT adds to Sayer's ME approach an in-depth understanding of changing employment and work practices in the context of wider dynamics in the political economy (Thompson and Newsome, 2004). Here, the social relations of production are conceptualised as contested, and LPT offers a strong conceptualisation of conflict and compromise at work that is based on the competing and under specific circumstances overlapping workplace concerns capital and labour have in the context of the structured asymmetry of employment. ME enhances an understanding of the relationship between employees and their managers as not only an economic relationship that is driven by workplace concerns, but also as a social and moral relationship. Here, the 
relationship between employees and managers is conceptualised as being fused with peoples' complex needs, moral evaluations and understandings as interdependent and sentient beings in the context of the structured antagonism of employment. In this way, Sayer's ME adds a strong account of individual agency and moral dimensions of employment to LPT, enabling a focus on the different strands of workers' and managers' actions, experiences and relationships at work that are influenced but not determined by their position in the labour process (Sayer, 2007). Overall, this article argues that the theoretical lens of ME and LPT offers a rounder picture for analysing changes in work and employment and their social and relational consequences.

\section{Method}

The article draws on data from a wider research project conducted between 2010 and 2012 which aims to capture employees' and managers' lived experience of the radically changing workplace regime in UK banks over the last three decades. Analysis is informed by data comprising 39 in-depth qualitative interviews with bank workers and managers from five retail banks in the UK. Overall, interviews lasted between one and three hours and culminated in 82 hours of interview material. Out of the thirty-nine interviewees, thirty-four were employed in a range of non-managerial positions, whilst five interviewees hold a managerial position in a bank. Based on this sample, three distinctive groups of bank employees and managers can be differentiated. One group consists of seventeen interviewees who entered the banking industry in the late 1970s and throughout the early 1980s; eleven individuals were interviewed who started their employment in the banking industry between the mid-1980s and early nineties. The final group of interviewees consists of eleven individuals who worked for a bank from the mid-nineties and early 2000s onward. 
All five banks are leading national banks in the UK who dominated the financial market for large parts of the $20^{\text {th }}$ century and continue to belong to the group of the most profitable clearing banks after the liberalisation of the financial industry and its financial crisis. Interviewees are almost equally spread across the five banks, with nine interviewees working for clearing bank 1-3 respectively, seven interviewees work for the fourth clearing bank. The remaining four interviewees were employed at the fifth bank. Even though differences in regards to corporate strategies, market share, total number of employees and branches exist between the leading national banks (Watson, 2004), previous research suggests that the banking industry is and has been traditionally homogenous when it comes to the organisation of work and management practices in branches (Halford et al., 1995). Indeed, as a reaction to the financial crisis, all banks involved in the study engaged in the post-crisis environment of labour cost-cutting, increased productivity expectations of their staff, and branch closures.

All interviews were with consent digitally recorded and transcribed. The analysis of the empirical material rests on several cycles of analysis that included thematic manual coding and a categorisation of themes in 'first-order' and 'higher-order' codes, using NVIVO, a qualitative data analysis program. Thematic analysis was conducted to identify recurring themes in the narratives. Based on this process, first order codes were created that used labels to describe the lived experience of interviewees ('close performance monitoring'; 'lack of discretion'; 'conflict with supervisors') that informed higher order codes which represent more abstract notions under which the first order codes were categorised together ('managerial control'; 'nature of work'; 'relationships between workers and managers'). To guarantee anonymity, biographical and organisational details and names of all interviewees have been changed.

At the heart of this article are narratives that reflect and make sense of their experiences of the labour process and its social relationships. However, narratives of the past 
inevitably bear the problem that interviewees' memory and recollection of events might be imprecise and clouded by nostalgia. Indeed it has been argued that narratives of the past reveal more about peoples' contemporary situation rather than presenting an accurate picture of the past (Gabriel, 1993). While it cannot be ruled out that nostalgia plays a role for interviewees recollection of the labour process and its social relationships under the pre-PMS workplace regime, the narratives are neither uncritical of the pre-PMS labour process nor contradicting findings of previous research on the banking industry. Hence, even though recollections of past incidents bear the risk of being imprecise, they should not be devalued, as they offer a unique opportunity to reveal interviewees' attachments to things that matter to them and their sense making of the present in the light of the past.

\section{Pre-PMS Branch work and its management}

Branch workers and managers who started work in the oligopoly banking industry in the late 1970s and early 1980s describe their work with words such as 'craft', 'professional' and 'meaningful'. At the heart of these positive characterisations are shared control concerns of employees and managers that are embodied in a 'whole-case' working approach that rests on the following of work tasks until completion, the absence of pro-active frontline management and the prevalence of informal work-effort norms (Edwards et al, 2006). In this environment the role of BMs concentrated primarily on supporting bank clerks with work issues and allocating work tasks to teams and individuals.

The branch manager was not looking over your shoulder and supervisors were not bothering you too much. You were expected to do your job well, but there was no 
stick and no close monitoring. We knew when and how to process things. (Melissa, BW, started in 1980)

In the context of a stable internal labour market that rewarded seniority and loyalty, BMs and their assistants were traditionally experienced bank clerks who were employed in a variety of clerical positions for a decade or two before reaching a managerial position. Despite BMs high level of accountability to senior management in regional centres, their work was characterised by relatively high levels of discretion in regards to the daily management of the labour process.

Branch managers were encouraged to think of their branch as a mini-bank that they own. They were given leeway for deciding everyday business decisions and how to manage staff in a way they considered to be best for the branch and best for the employees. (Steve, BM, started in 1981)

In the oligopolistic financial market, bank work featured privileged working conditions that triggered overlapping control and development concerns between BWs and BMs (Edwards et al., 2006). Yet, the relationships between BWs and BMs went beyond shared workplace interests, embodying a social and moral web that embedded the labour process.

\section{Pre-PMS social relationships between branch workers and their managers}

A pivotal theme in the narratives is the experience of a social structure of respect between BWs and BMs. Several narratives illustrate that BWs respect was grounded in the clerical and technical expertise BMs were believed to possess, but also the way BMs represented and 
embodied the occupation and its social and moral order through clerical background and loyalty to the organisation.

The branch manager was an outstanding member of the community. Back in the 1970s and 1980s branch managers have been at the floor and went through clerical jobs before they reached a managerial position. We all had the utmost respect for him. (Diane, BW, started in 1979)

The shared experiences of the labour process enabled BMs to relate and sympathise with the work branch staff performed and the struggles they were facing on a daily basis. The respect BWs received from BMs was encoded in the way they were trusted to do their job well, but also entailed traces of unconditional respect for the person occupying the job, enabling BWs to understand themselves as object of value (Sayer, 2006).

'Branch managers treated staff with respect. They did not look down on you. They valued you as a person. There was no condition of you outperforming everyone else to get recognition from management'. (Amanda, BW, started in 1986)

Albeit it is not suggested that the social relationships between both groups undermined the ubiquitous power asymmetries between capital and labour, narratives point towards the embeddedness of the labour process in a social and moral web that rested on shared moral understandings. This is evident in BWs' narratives that describe the experience of BMs concern for their faring not only as a factor of production, but also as a sentient individual (Sayer, 2011). 
When my auntie died the manager took me aside and talked to me about it. He showed concern and was there for me. This was not about 'when will you be $100 \%$ again for work', but this was a human concern. There was that sort of care and understanding of social and human problems. (Susan, BW, started in 1972, retired in 2006)

Yet, the labour process and its social relationships were interwoven with inequalities and power asymmetries that structured the employment relationship. Indeed, narratives suggest that patriarchal values were deeply ingrained in the workplace regime. This is evident in testimonials that reveal career structures and skill formation systems under the pre-PMS as fostering a 'gender order' (Crompton, 1989) that resulted in high levels of sexual division of labour and overt and covert discrimination against female bank workers.

It was not common sense back then that we would do the same training as our male colleagues. But getting banking certificates would give you the edge. So [they made] it a hassle for us to get into these classes. But let us not forget that discriminative practices, like marriage bars, are recent history in banks. Branch and assistant managers were usually recruited form the old boys club (Hazel, BW, started in 1989).

\section{The marketisation of branch work and the rise of PMSs}

The nature of bank work changed radically throughout the early 1990s when waves of organisational restructuring re-designed bank branches as retail units in which work became predominantly sales driven. The proliferation of marketing and sales tasks was experienced by BWs as a degradation of their formerly conservative and service oriented clerical 
occupation that is manifest in cynical descriptions that characterised bank work as 'increasing, towards customers wallets' (Mick, BW, started in 1984) and being primarily about 'hunting customers' (Brent, BW, started in 1986).The heightening of pro-active sales work was accompanied by a Taylorisation of bank work that is encoded in the implementation of PMSs that rested on time and motion measurements from which team and individual performance targets were derived. BWs experienced a decline of task discretion thanks to the integration of sophisticated ICTs that were used to standardise work processes and the division of formerly interdependent work tasks into small sets of measurable jobs that became subject to close monitoring by supervisors.

We felt that the switch to measuring performance was very fast and over the top. They tried to capture every single thing that we do here. No stone was left unturned. Corporate management developed measurements for every job and task they could think of. (Judith, BW, started in 1975)

In the context of intensified competition in the financial market individualised performance and output norms for BWs replaced the formerly informal work effort norms and became increasingly demanding in the late 2000s, peaking in observations of BWs that the required performance was unachievable. The escalation of performance targets went hand in hand with the introduction of disciplinary policies that threatened employees who did not meet their targets with punitive practices, which ranged from formal warnings to involuntary exit. In this way, job security was directly linked to BWs ability to meet performance norms, pointing towards a 'collectivisation of effort and decollectivisation of risk' (Burchell et al., 1999: 60). 
Targets are going up for the last few years. (...) It is hard to meet targets all the time, especially in the current economic climate. Many have been labelled in the past as underperformers. The real threat is to be labelled as underperformer twice within a year as management tries to push underperformers out the door. (Bob, BW, started in 1996)

Within the changing labour process of branch work, branch management experienced a significant degradation of their discretion for managing staff, while their role in the branch transformed radically.

\section{The transformation of branch management: From paternalism to monitoring and disciplining}

Under the performance driven regime performance targets were designed and cascaded down by senior managers in regional centres with little to no involvement of BMs. The erosion of the formerly high levels of discretion BMs experienced in the context of the implementation of a centralised PMS s that requires them to engage in prescribed and repetitive forms of micro-managing and disciplining staff suggests that the degradation of the work and role of BWs and BMs in the labour process have much in common.

My work consists of collecting sales statistics, following procedures, passing on targets to teams and individuals, applying disciplinary policies and so on. It is called 
management, but it is really just ticking the box and pushing employees, executing decisions that have been made elsewhere. (Hans, BM, started in 1995)

The degradation of BMs autonomy and authority went together with the tightened control over their work via the implementation of accountability measures, encapsulated in detailed performance targets and close monitoring by senior management. Unsurprisingly, common themes in the narratives are experiences of powerlessness and vulnerability vis-à-vis a system that places pressure on BMs from above and below. In this environment, BMs translated performance pressures into tighter control over branch staff, resulting in a disconnection of the formerly shared control and development concerns between BMs and BWs and a decline of shared moral understandings (Edwards et al., 2006; Sayer, 2006).

I need to constantly animate, push and stretch staff so that the branch meets its target, because if the branch does not hit its target it is not just staffs head on the line but mine as well. Not just employees are walking on eggshells, management is too. (Danny, BM, started in 1990)

\section{The rise of antagonistic relationships between branch workers and managers under PMS}

With the rise of PMSs and the marketisation of the employment relationship, low-trust and conflict ridden engagements between branch management and employees increased significantly, shaping everyday interactional realities. Low-trust relationships were enmeshed in BWs perception of BMs as the personalisation of a system that subordinates them under 
the dictate of performance expectations. At the heart of these sentiments are BWs' evaluations of the PMS as a workplace regime that treats employees as factors of production, narrowing their multiple interests and concerns down to those that are essential for meeting market demands (Sayer, 2006).

Branch managers became supervisors and glorified sales managers. They are doing less things now, they are just there to drive sales. For them it is all about pushing us as hard as possible to achieve the targets. There is little room for care for human problems. (Jenny, BW, started in 1976 and retired 2011)

The dominance of conflict-ridden relationships between both groups is particular evident in the hostile attitude of experienced BWs towards a new generation BMs who were recruited from outside the banking industry and possessed limited experience of bank work. BWs hostility is encoded in dismissive descriptions of BMs as 'clueless', 'useless' and 'tools', exemplifying the shift of a social structure of respect to antagonistic and dehumanised relationships. In turn, BMs who were recruited under the PMS regime tended to align their interests with the PMS mantra, embracing the instrumental and market driven nature of bank work.

We need to create profit for shareholders and hit the targets. That is why I am here and that is why they [branch workers] are here as well. If you create value you deserve more money than someone who is pushing papers and selling standardised products. (Ken, BM, started in 2004) 
The conditionality and disconnection between BWs and BMs fed a vicious circle of distrust, disrespect and self-survival that deprives actors of human connections and spaces for care and sympathy (Sayer, 2007). Narratives illustrate that both groups engaged in a negative framing process of the respective other as possessing hostile and harmful intentions, triggering dehumanised and often personalised conflicts that include but go beyond managerial abuse and open displays of disrespect.

I complained recently about one specific manager and the manager actually said to me "if you are having a go at me, I am going to have a go at you". That is the way they think. (Rory, BW, started in 1996)

Staff and managers pick on each other a lot lately. It is very difficult to go to work sometimes because of the pressure and disrespectful practices, like sending emails in capital letters, shouting at each other. (Diane, BW, started in 1979)

Against the backdrop of degradation of work and measurement of targets and application of disciplinary policies that took precedence, narratives display a strong concern about a labour process that objectifies and deprives them of recognition, trust and empowerment, leaving little space for human connection.

\section{Traces of reconnection}

Even though conflict was a pivotal feature of the labour process, some testimonials suggest that temporary re-connections between BMs and BWs occurred over their shared assessment 
of and moral outrage at a workplace regime that renders people powerless while violating lay notions of fairness and justice (Sayer, 2011).

In the appraisal meeting my manager asked 'how do you see yourself developing at work?' and I told him 'this work prevents me from developing'. I am lucky because my manager is cool with me, he is not a robot. Once I told him: 'The company is full of shit, it treats the customer like trash and takes as much money as they can get and treats us like shit as well'. He just nodded and said 'I know'. He knows what is going on and he doesn't mind talking about how things really are. I am safe with him. (John, BW, started in 1982)

However, shared moral understandings between both groups were rare thanks to the instalment of a new generation of BMs as target and disciplinary policies enforcing supervisors who were recruited on the basis of their support for the PMS. Nevertheless, the case of Ciara suggests that peoples' shared experiences from outside the labour process can enable them to search for ways to improve and re-humanise the employment relationship. Being active in the union before becoming a BM, Ciara experienced compassion for the pressure employees faced. After fighting senior management over targets she deemed impossible to meet while facing staff shortage, she told senior management 'that they have to send someone to run this branch because I am going home' (Ciara, former BM, started in 1998). Ciara stopped working in the branch shortly after this incident. Yet, her concern regarding the faring of her fellow workers was not limited to the grievance she aired and decision to exit the organisation, but is also at the heart of her current work as a development 
officer. In that capacity, she offers union-led workplace training, supporting BWs to gain a voice in the labour process.

\section{Discussion and conclusion}

The utilisation of Sayer's ME approach in tandem with LPT offers a novel framework that connects the theoretical strands of changing practices in work and employment against the backdrop of political economy as a structural context that fosters a structured antagonism between labour and capital fuelled by the indeterminacy of labour and capitalists aim to control it (Edwards, 1979; Smith, 2006) with a strong account of people as reflective, interdependent and lay moral actors who have complex needs and concerns (Sayer, 2006; 2011). Bringing LPT and ME together allows a conceptualisation of relationships between employees and managers as a multi-layered and dynamic control, social and moral relationship. The combination of these two analytical strands theorises social relations at work as suffused with people's lay morality and normative understandings on the one hand while being shaped by the constraints and enablers workplace regimes hold for the competing rationales between capital and labour and human (dis)connection on the other (Edwards et al., 2006; Sayer, 2008). Such a focus allows an analysis of if and how the instrumental frame and material reality of the labour process is mediated and humanised, or reinforced and intensified, by employees' and managers' relationships. The changing labour process and relationships between employees and managers in UK banks in the context of the marketisation of the employment relationship and the implementation of PMSs showcases how the combination of LPT and ME provide a valuable theoretical approach for analysing the social, relational and moral consequences of work and employment. 
In the context of the relatively privileged employment conditions in UK banks under the pre-PMS workplace regime, the article reveals that the labour process was embedded in a social compromise between capital and labour and shared moral understandings (Edwards et al., 2006). This is encoded in overlapping control and development concerns between BWs and BMs and a lay morality that rendered the respective other not only as an economic, but also as social and sentient being with diverse needs and concerns, resulting in displays of respect, recognition and care (Sayer, 2005). Even though open conflicts were largely absent in the pre-PMS workplace regimes, the LPT and ME lens adds nuance to an understanding of how struggle and conflict at work bubbled under the surface of the employment relationship. Conflict between people's lay morality and the inequalities of the pre-PMS workplace regime is inherent in the persistence of patriarchy in banks that rendered female branch workers inferior to their male colleagues. However the co-existence of discriminative practices with shared moral understandings does not imply a corruption of moral sentiments in workplaces. Instead, it illustrates the complexity of social and moral relationships between dominant and subordinated groups that rest on moral understandings that are unevenly accomplished and thereby selective and fallible (Sayer, 2000, 2011). Hence, a social and moral web at work cannot be interpreted as a countermovement to the power and control relationships that are structured within workplace regimes under capitalism, but rather as a dynamic and conditional moral understandings within the structured asymmetry of the employment relationship that represent selective attempts to humanise it.

The article reveals the degradation and intensification of work BWs and BMs are subject to under PMSs that is embodied in detailed performance targets, close work effort monitoring and 'harsh' disciplinary policies. The theoretical lens of LPT and ME provides an enhanced understanding of the market driven conditionality of the performance driven workplace regime that embraces a risk shift from the employer to the employee via an 
individualisation of risks and rewards (Thompson, 2011). A striking feature of BWs' and BMs' labour process is their experience of relative powerlessness vis-à-vis ever increasing performance targets and the ubiquitous threat of dismissal. In this way, the combination of the focus of LPT on changing workplace practices with Sayer's thick conceptualisation of people as social and moral beings illustrates the employment relationship in banks as degraded and highly commodified labour process that narrows down BWs and BMs complex needs and concerns to those essential for meeting market needs (Edwards et al., 2006; Sayer, 2007). The article argues that the precedence of a market logic in the labour process has disruptive consequences for human engagement and social relationships, as testimonials of rising levels of self-protective and competitive behaviour in the branch suggests.

However, the relationships between BMs and BWs go beyond competitiveness and instrumentalism, featuring expressions of hostility and overt conflict between both groups. The combination of ME and LPT suggests that the shift towards conflict-ridden relationships in banks can be interpreted in two complementary ways that showcase the strength of the theoretical lens. First, the rise of antagonistic relationships are ingrained in the competing control and development concerns of labour and capital that are translated into the branch and everyday interaction realities (Edwards et al., 2006). In this way, open conflicts at work are driven by disagreements between BWs and BMs over the nature of work, the quality and quantity of targets and the application of disciplinary policies (Bélanger and Edwards, 2007). Conflict over workplace conditions are particularly evident in the hostile relationships between experienced BWs and the new generation of BMs who were placed as constrained supervisors in the labour process and recruited on the basis of their acceptance of the PMS mantra. Thus, it can be argued that conflict is structured within the employment relationship.

Following on from this, the conceptualisation of the relationship between employees and managers as control, but also social and moral relationship enables an understanding of 
how the conflict over workplace concerns escalates towards hostile forms of engagements and often personalised conflicts. In the context of the marketised labour process that embraces self-survival and instrumental engagements with work and relationships, narratives provide ample evidence that the relational give and take that is essential for human and moral connections is undermined. The dismantling of the social and moral web was experienced by BWs as a violation of their moral understandings, as their evaluation of the labour process as resting on an unfettered commodification of their labour that has little regard for human wellbeing and social concerns shows (Sayer, 2007). BWs' moral evaluations are informed by their experiences of the valued pre-PMS workplace regime and the shared moral understandings if fostered. However, the new generation of branch managers who lack the shared experiences of the pre-PMS labour process tend to accept the market driven conditionality of the labour process, while evaluating BWs' sense of injustice as a sign of their inadaptability to the changing employment conditions. In this way, the antagonistic and hostile relationships at work are fuelled by fundamentally different moral understandings regarding the nature and meaning of work and how employees and managers should treat each other (Sayer, 2006). The disconnection of moral understandings leads to a personalisation of the conflict over workplace concerns, resulting in hostile relationships, illtreatment and, ultimately, a decline of well-being. This is manifest in narratives that portray the respective other as having competing and indeed hostile intentions, while expressing concern of not being treated as an individual but rather as an object. However, this article does not suggest that human re-connection is impossible between BWs and BMs, as the example of Ciara suggest, but evidence implies that opportunities for shared moral understandings are limited.

In conclusion, this article contributes to the critical workplace studies on the changing nature of white collar employment (e.g. Carter et al., 2014; Hassard et al., 2009; Halford et 
al., 1995), providing an-in-depth account of the radically changing labour process in UK banks and its consequences for the social relationships between BMs and BWs. Drawing on in-depth interviews with branch workers and managers, the novel framework of LPT and ME captures the shift from a labour process that featured shared workplaces concerns and moral understandings between employees and their managers to a performance driven and individualised employment relationship in which competing workplace concerns and disconnected moral understandings contribute to hostile and conflict-ridden relationships between both groups. By arguing that the PMS driven workplace regime prioritises market needs over human needs and strips many of the human and social texture out of the workplace, an ample warning is provided regarding the impact a purely target and marketised workplace regime has on people and, ultimately, the society.

\section{Acknowledgements}

I would like to thank Ian Clark, Chris Forde and the three anonymous reviewers for their insightful comments.

Knut Laaser studied socio-economics and sociology in Hamburg and at the LSE. Knut is currently an Early Career Fellow at the University of Stirling in the Management School. His research is informed by critical social theory and focusses primarily on the changing nature of work and peoples' lived experiences. Amongst other articles he co-authored together with Sharon Bolton the article 'Work, employment and society through the lens of moral economy' in this journal. 


\section{References}

Bélanger, J and Edwards, P (2007) The Condition Promoting Compromise in the Workplace. British Journal of Industrial Relations, 45(4): 713-734.

Blackburn R (1967). Union character and social class: a study of white-collar unionism. London: Batsford.

Braverman H (1974) Labor and Monopoly Capital. New York: Monthly Review Press.

Carré F, Findlay P, Tilly C and Warhurst C (2012) Job quality: Scenarios, Analysis and Interventions. In Warhurst C, Carré F, Findlay P and Tilly C (eds.) Are Bad Jobs Inevitable? Trends, Determinants and Responses to Job Quality in the 21st Century. Palgrave: London, $1-22$.

Carter B (1985) Capitalism, Class Conflict and the New Middle Class. London: Routledge and Kegan Paul.

Carter B, Danford A, Howcroft D, Richardson H, Smith A and Taylor P (2014) ‘They can’t be the buffer any longer' : front-line managers and class relations under white-collar lean production. Capital and Class 38(2): 323-343.

Cressey P and Scott P (1992) Employment, technology and employment in the UK clearing banks: is the honeymoon over? New Technology, Work and Employment 7(2): 83-96.

Crompton R and G Jones (1984) White Collar Proletariat: Deskilling and Gender in Clerical Work. London: Macmillan. 
Crompton, R (1989) Women in Banking: Continuity and Change since the Second World War. Work, Employment and Society 3(2): 141-156.

Edwards R (1978) The Social Relations of Production At the Point of Production. Critical Sociology 8( 2-3) 109-125.

Edwards R (1986) Conflict at Work. Oxford: Blackwell.

Edwards PK, Bélanger J and Wright M (2006) The Bases of Compromise in the Workplace: A Theoretical Framework. British Journal of Industrial Relations 44(1): 125-146.

Ellis V and Taylor P (2006) 'You don't know what you've got till it's gone': recontextualising the origins, development and impact of the call centre. New Technology, Work and Employment 21(2): 107-122.

Ellis V and Taylor M (2010) Banks, bailouts and bonuses: a personal account of working in Halifax Bank of Scotland during the financial crisis. Work, Employment and Society 24(4): 803-812.

Fevre R, Lewis D, Robinson A and Jones T (2012) Trouble at work. London: Bloomsburry Publishing.

Gabriel Y (1993) Organizational nostalgia: Reflections on the golden age. In Fineman S (Ed.) Emotion in Organizations, London: Sage, 118-141.

Gall G (2008) Labour Unionism in the Financial Services Sector: Fighting for Rights and Representation. London: Ashgate Publishing.

Halford S and Savage M (1995) Restructuring organizations, changing people: gender and restructuring in banking and local government. Work, Employment and Society 9(1): 97-122

Hassard J, McCann L and J Morris (2009) Managing in the Modern Corporation.

Cambridge:Cambridge University Press.

Heritage J (1977) The growth of trade unionism in the London clearing banks 1960-1970: A sociological interpretation. Leeds. Unpublshed PhD.

Korczynski M and Ott U (2005) Sales work under marketization. Organization Studies 26(5): 707-28. 
Lapavitsas C (2011) Theorizing financialization. Work, Employment and Society 25(4): 61126.

Lockwood, D (1958) The Black-Coated Worker: A Study of Class Consciousness. London: Allen and Unwin.

Newsome K, Thompson P and Commander J (2013) 'You Monitor Performance at Every Hour': Labour and the Management of Performance in the Supermarket Supply Chain'. New Technology, Work and Employment 28(1):1-15.

Polanyi K (1957) The Great Transformation. New York, NY: Rhinehart

Polanyi K (1968) Our obsolete market mentality. In: Dalton G (ed.) Primitive, Archaic and Modern Economies: Essays of Karl Polanyi. Boston MA: Beacon Press, 59-77

Sayer A (2000) Moral economy and political economy. Studies in Political Economy 61(2): 79-103.

Sayer A (2005) The Moral Significance of Class. Cambridge: Cambridge University Press.

Sayer, A (2006) Instrumentalism and after: or: the good, the bad and the instrumental. In: Wood G \& James P (eds) Institutions, production and working life. Oxford: Oxford University Press, 203-216.

Sayer A (2007) Moral economy and employment. In: Bolton SC and Houlihan M (eds) Searching for the Human in Human Resource Management: Theory, Practice and Workplace Contexts. London: Palgrave, 21-40.

Sayer A (2011) Why Things Matter to People: Social Science, Values and Ethical Life. Cambridge: Cambridge University Press.

Smith C (2006) The double indeterminacy of labour power: labour effort and labour mobility. Work, Employment and Society 20(2): 389-402.

Taylor P (2013) Performance Management and the New Workplace Tyranny: A Report for the Scottish Trades Union Congress. Glasgow: Strathclyde University.

Thompson, P (1989) The Nature of Work: An Introduction to Debates on the Labour Process. London: Macmillan. 
Thompson P, Smith C and Ackroyd S (2000) If ethics is the answer, you are asking the wrong questions: a rejoinder to Parker. Organization Studies 21(6): 1149-1158.

Thompson P and Newsome K (2004) Labour process theory, work and the employment relation. In Kaufman BE (ed.): Theoretical Perspectives on Work and the Employment Relationship. Cornell: Cornell University Press, 133-162.

Thompson P (2011) The trouble with HRM. Human Resource Management Journal 21(4): 355-367.

Thompson P (2013) Financialization and the workplace: extending and applying the disconnected capitalism thesis. Work, Employment and Society 27(3): 472-488.

Watson K (2004). The financial services sector since 1945. In: Floud R J (Ed.): The Cambridge Economic History of Modern Britain. Cambridge: Cambridge University Press, 167-187. 